\title{
La pandemia de CoviD-19 en México y la otra epidemia
}

\section{The CoviD- 19 pandemic in Mexico and the other epidemic}

Francisco Pamplona

\begin{abstract}
Resumen
Desde una perspectiva sociológica, y sobre la base de datos publicados por la Secretaría de Salud sobre la pandemia de CoviD-19 en México, se describe la situación de los servicios médicos, la infraestructura de salud y los efectos de la obesidad, la diabetes y la hipertensión en el significativo número de muertes. Se analiza la probabilidad de infectarse y fallecer en asociación con dichas comorbilidades. Resultados: desde la década de los 80 no hay un cambio significativo en los servicios, ni en la infraestructura para la salud; en ese periodo hubo un incremento exponencial de enfermos de diabetes, de hipertensión y obesidad; del total de muertos por coviD-19 registrados hasta la fecha de análisis, el $65.8 \%$ padecía al menos una de las tres co-morbilidades; finalmente, la probabilidad de fallecer por CoviD- 19 se incrementa en los hombres mayores de 54 años que padecen alguna co-morbilidad.
\end{abstract}

Palabras clave: CovID-19, diabetes, obesidad, hipertensión; infraestructura y servicios de salud

\begin{abstract}
With a sociological perspective and based on data published by the Ministry of Health on the Covid-19 pandemic in Mexico, this paper describes the situation of medical services, health infrastructure and the effects of obesity, diabetes and hypertension on the significant number of deaths. The probability of becoming infected and dying is analyzed in association with comorbidities. Results: since the 1980s there has been no significat change in health services, neither in health infrastructure; in that period there was an exponential increase in patients with diabetes, hypertension and obesity; From the total number of CoviD-19 deaths registered up to the date of analysis, $65.8 \%$ suffered from at least one of the three co-morbidities; finally, the probability of dying from COVID-19 increases in men over 54 years of age who suffer from some co-morbidity.
\end{abstract}

Keywords: CovID-19; diabetes, obesity, hypertension, infrastructure and health services

\footnotetext{
- Doctor en Ciencias Sociales con orientación en Sociología. Profesor investigador del posgrado en Humanidades y Ciencias Sociales de la Universidad Autónoma de la Ciudad de México y profesor de asignatura en la Facultad de Filosofía y Letras de la Universidad Nacional Autónoma de México. Investigador nacional. Orcid: 0000-0002-7995-9809 / francisco.pamplona@uacm.edu.mx. Fecha de recepción: 23 de julio de 2020. Fecha de aceptación: 31 de agosto de 2020.
} 
En términos generales y seriamente, hay que decir que toda voluntad de mejora orgánica pende en el vacío, si no se conoce y no se tiene en cuenta la voluntad de mejora social. La salud es un concepto social, como lo es la existencia orgánica del hombre como hombre en su totalidad. Y la salud, por eso, solo es acrecentable con sentido cuando la vida en la que está situada no se ve agobiada por la angustia, la miseria y la muerte.

Ernst Bloch, El principio esperanza (1959)

\section{Los rasgos de la pandemia}

La pandemia no ha terminado. Mientras escribo, los números de pruebas, de contagios y de muertes siguen creciendo y parece - al menos en una buena parte del mundo-, que el mal, una vez instalado, no da lugar para una reflexión sosegada de lo que velozmente se nos presenta, y que la perspectiva de obtener un tratamiento eficaz o un medio preventivo seguro, está sometida a la debilidad del progreso científico instantáneo y a la lógica del dinero, lógica que incluso trata de arrebatar ese futuro incierto; lo que está en juego para una abrumadora mayoría es una manera de vivir, sea para sostenerla pese a todo o para dinamitarla sin hacernos la engorrosa pregunta de lo que vendrá después.

Lo que se ha puesto a prueba con la pandemia es la pregunta de si la enfermedad que causa el nuevo virus tiene realmente el potencial de hacer tanto daño como para frenar el mercado global, más allá de lo aconsejable; es decir, como si esa enfermedad en particular no pudiera someterse a la estadística general de pérdidas humanas por otras causas, de cifras devastadoras y claramente diferentes entre clases e individuos. ¿Cómo resarcir el daño ya provocado por el encierro de millones de personas que dejaron de producir y consumir bajo las formas establecidas, mientras que otras, bajo su cuenta y riesgo, tuvieron que salir a ganarse la vida exponiéndose y exponiendo a otros? 
La pandemia introdujo un dinamismo social diferente al habitual: quienes tuvieron los medios (dinero seguro, trabajo seguro), se convirtieron en usuarios emergentes de tecnologías de comunicación e información que han difuminado el contacto físico con sus audiencias, familias, amistades. Otros, tratando de superar su propia condición, se transformaron sin rechistar en productores de nuevas mercancías y en consumidores también sobrevivientes de esas mercancías de nueva factura. Desde los negocios se ha tenido que lidiar con nuevas formas de comprar y vender. Ha crecido, aunque sea temporalmente, una forma de altruismo sin generosidad, un dar porque no hay de otra, y desde instituciones públicas y privadas, desde organizaciones sociales, y de manera muy notoria desde el espacio privado, se ofrecen entretenimiento y bienes culturales de todo tipo, incluso de manera gratuita. Será interesante saber hasta qué punto las redes sociales fueron saturadas a deshoras y en tiempo de conexión. ¿Se transita hacia un cambio auténtico?

Lo que comienza a aparecer es una forma de impaciencia social indiscernible porque tiene muchos orígenes o puntos de partida individuales. Inquietud y temor combinados sin acción libre que ataje el tedio siempre al acecho. Salir a la calle se transformó para muchos, para los jóvenes en particular, en una consigna solo realizable en la observación del cambio de color de un semáforo. Las fiestas y visitas a lugares turísticos en Europa después del desconfinamiento son una muestra clara de lo anterior, como si la humanidad estuviera hincada en la línea de salida para correr una distancia no medida y sin tiempo para hacerlo: el pistoletazo que anuncia el arranque es potencialmente uno que alerta y ordena a la cabeza regresar -aunque refunfuñando- al encierro.

La pandemia también trata de números, o muy especialmente de ellos, pues también desde ahí se quisiera asegurar 
el éxito o el fracaso de las intervenciones gubernamentales por una parte, y por otra las formas de comportamiento social, sin tomar en cuenta que siempre, durante las epidemias, hay alguien que rompe las rejas del encierro - por su cuenta o en complicidad con las autoridades-y expone a todos al juego de lo indeterminado y lo imprevisible. Siempre hay grupos e individuos a quienes la tentación de la juerga los vence y simplemente se pasan los altos. ${ }^{1}$

Los modelos matemáticos y epidemiológicos que tratan de advertir el curso de una epidemia en particular fracasan, al menos en parte, debido a que las medidas que son el sustento de una buena previsión no son atendidas por todos, sea por necesidad, sea por descuido, por incredulidad, por arrogancia frente a lo invisible, por superstición y creencia providencial, por escepticismo de lo que se informa desde el poder público, por irresponsabilidad, por descreer de la ciencia o por suplantar a la establecida por otras, múltiples, y a veces con soluciones mágicas y sencillas.

Desde el poder económico se acicatea la idea de que la cobardía acompaña al fracasado y al pobre, de que es preciso destruir los cotos de prevención para ganarse la vida. Este acicate es tremendo: subvierte el orden a favor de la acumulación y el incremento de la riqueza privada por sobre toda prudencia. También abundan canallas en las esferas de la decisión pública que, durante las epidemias, intentan suprimir las libertades y los derechos: ensayan el estado de excepción con toques de queda simulados o con medidas de control innecesarias. ${ }^{2}$

I. Cipolla, Carlo (1984). ¿Quién rompió las rejas de Monte Lupo? Barcelona: Muchnik. Este cuidadoso y delicioso estudio sobre la epidemia de la peste en la toscana en el siglo XVII nos ayuda a comprender los efectos de tales desbordamientos sociales y la complicidad que tienen algunas autoridades.

2. En un ensayo publicado en 2016 sobre la sociología jurídica y el estado de excepción en México en la epidemia de A/HINI de 2009, argumenté que esas tentaciones se podían convertir en práctica gubernamental habitual o recurrente sin que se advirtiera claramente su contenido, más allá de algunas denuncias en medios informativos.Véase: Pamplona, Francisco."Epidemias y política. Reflexiones 
Los números de contagiados, de muertos, de sobrevivientes que arrojan las epidemias son crecientes (a veces con ritmo acelerado los contagios y las muertes) durante algún tiempo, muchas veces indeterminado, sobre todo por las producidas por nuevos agentes infecciosos; luego, esos números decrecen, se archivan sus resultados y se pasa a lo que sigue. La actual pandemia es cuantificada diariamente en el mundo y en cada uno de los países; los medios de procesamiento y difusión de la información así lo permiten y, por primera vez, con diferencia de horas y minutos, quienes tienen acceso pueden informarse, pero en ese proceso pueden, con mayor probabilidad, desinformarse, pues los números son utilizados de manera sesgada, insidiosa, ignorante de su sentido o de forma políticamente interesada. Es un hecho que la desinformación es la principal protagónica, no importa a quién sirva.

En México hay una disputa por las cifras y al igual que en muchos países se vive el fenómeno descrito en el párrafo anterior. Pero en nuestro país adquiere (al igual que en USA) la particularidad de estar inscrito en una coyuntura política de gran importancia, pues pronto habrá elecciones que marcarán el rumbo del país para los próximos años. Esta coyuntura hace que el vaivén información-desinformación sea tempestuoso; la relevancia de las cifras se quiere someter desde opiniones interesadas o desinformadas a la idea de que el manejo de la epidemia es un fracaso (los números crecen, sobre todo el número de muertos crece),

sobre el 'estado de excepción' desde la sociología jurídica”, en Estudios y testimonios en honor al Dr. Manuel Rodríguez Lapuente. Josefina Callicó y Evaristo Jaime González (Coord.). Gobierno del Estado de Jalisco, Guadalajara 2016,4l-66. Es de subrayar que el actual gobierno federal actúe - contra viento y marea- en un sentido más democrático, pues no ha impedido por medios autoritarios el ejercicio de la libertad y no se han violado derechos humanos; se optó por el convencimiento y por la insistencia de poner por delante la importancia de las medidas de prevención de salud pública. 
mientras que el argumento oficial (los números, ¿qué tanto crecen?) es que gracias a las medidas tomadas no hay una catástrofe, dada la situación de la salud pública heredada (infraestructura, recursos, financiamiento, etcétera).

En este artículo se proporciona información precisa para que quienes lo lean puedan formarse un juicio más detallado de la situación -y en menor medida de la evolución- de la pandemia en México del virus Sars-Cov2 y la enfermedad que causa, covid-19.

\section{La pandemia de coviD-19 en México}

Hasta el 22 de julio de 2020 se habían realizado 861,852 pruebas para detectar por la técnica de PCR al coronavirus Sars-Cov2, de las cuales 411,673 resultaron negativas (47.8\%), 362,274 resultaron positivas $(42.0 \%)$ y se habían acumulado 41,190 defunciones $(11.4 \%$ con respecto a los positivos); la cifra real de pruebas positivas podría incrementarse a esa fecha hasta 402,710, tomando en consideración el porcentaje de positividad (46) sobre los casos sospechosos que había acumulados, 87,905.

Estos grandes números están en disputa, pues se dice (muy pocas veces se argumenta) que son muy grandes, incluso sabiendo que debe haber un punto de comparación y que esta se debe sujetar a criterios de estandarización y comparabilidad sólidamente establecidos en los métodos matemáticos y estadísticos, en los procedimientos demográficos y epidemiológicos. Tratándose de un fenómeno que causa sufrimiento, las cifras absolutas son sumamente relevantes, sobre todo la de los muertos. La relatividad de las cifras y los procedimientos de comparabilidad no son un atajo para evitar el señalamiento de la crudeza epidémica, sino de situar en una magnitud aprehensible los datos pandémicos. 
Gráfica 1a. Evolución de la epidemia de COVID-19

(Casos confirmados más 46\% de sospechosos)

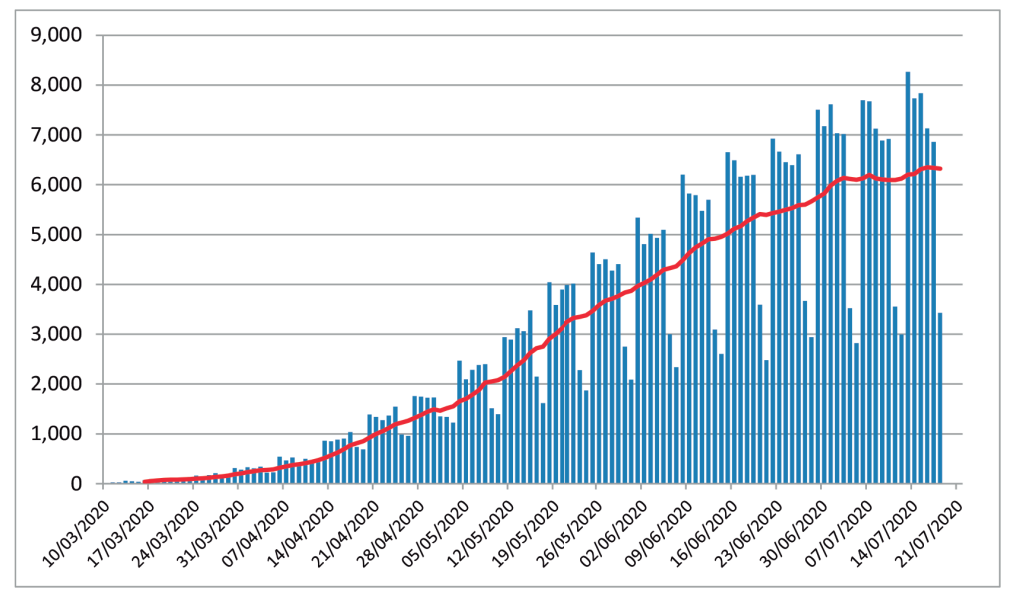

Del 1 de enero al 22 de julio había registrados 362,274 casos confirmados, más $46 \%$ de sospechosos, fueron 402,710 casos estimados.

Gráfica 1b. Evolución de la epidemia de CovID-19

(Defunciones confirmadas)

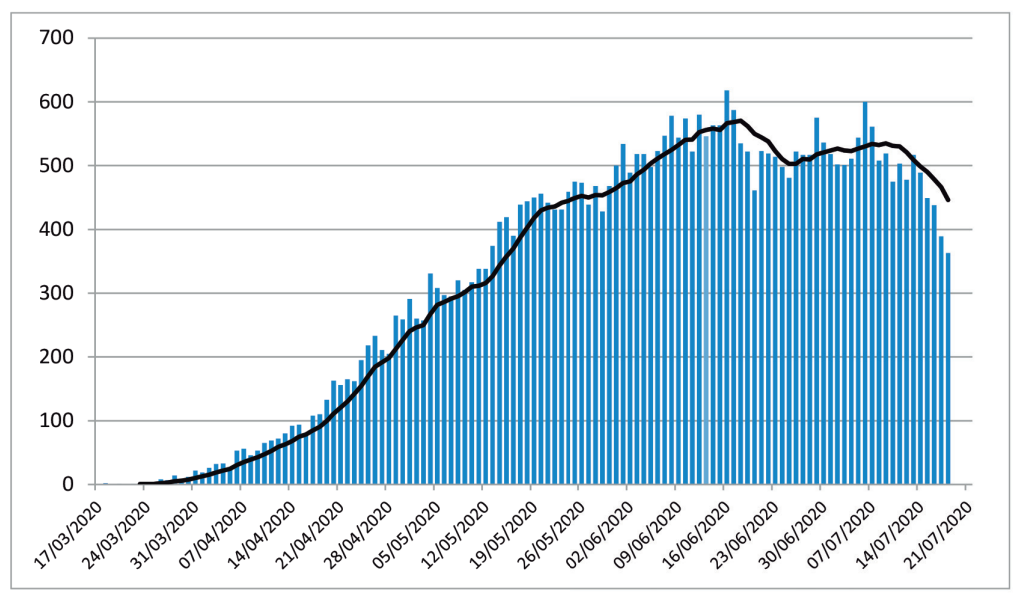

Del 17 de marzo al 22 de julio había registradas 41,190 defunciones confirmadas. 
La gráfica 1 muestra la evolución de la pandemia de CoviD-19 en México; las fechas de referencia corresponden, la primera, a la confirmación del primer caso, el 12 de enero (se registró un caso sospechoso en una fecha anterior); en el caso de las defunciones, al primer muerto de CoviD-19, confirmado el 17 de marzo. Ambas partes de la gráfica muestran el crecimiento de la enfermedad (o síndrome) y en las líneas correspondientes, el promedio móvil de siete días; se observa, hacía la cúspide de las curvas, una estabilización o un franco descenso en las últimas semanas, fenómeno más notorio en el caso de las defunciones. La pregunta, para muchos apremiante, es si esa tendencia es real o hay un ocultamiento de los datos por parte de la autoridad.

$\mathrm{Al}$ respecto caben dos observaciones que no se hicieron notar de manera inmediata y mucho más enfática, antes de que el número de defunciones creciera más allá de las predicciones de los modelos: la primera es sobre la confirmación del número de casos que en México se realiza por medio de la ya mencionada prueba de $\mathrm{PCR},{ }^{3}$ bajo los supuestos de un modelo de vigilancia epidemiológica, que consiste en la indagación de casos a partir de uno de ellos que ha sido confirmado; el rastreo intencionado poblacional de casos se hace en un periodo posterior a la vigilancia epidemiológica. Los procedimientos de pruebas rápidas no son un recurso confirmatorio robusto, pues arrojan resultados falsos, positivos o negativos, en proporciones muy altas; además, hay que subrayar que la prueba de PCR que se hace en México detecta al virus en su periodo infectante, o "en tiempo real".

La segunda observación es sobre el número de defunciones por Covid-19 y su registro; cualquier persona que haya tenido que realizar trámites para inhumar o disponer de los restos de un cadáver de un familiar o conocido sabe que lo

3. Simplificando, la prueba por medio de PCR, sigla en inglés de "reacción en cadena de la polimerasa", consiste en detectar material genético de un patógeno, en este caso el coronavirus SarsCov2, en las células del individuo infectado.

\section{2}


primero es obtener un certificado de defunción en el cual se anotan, entre otros datos relevantes del fallecido, las causas de muerte, sobre la base de la Clasificación Internacional de Enfermedades, o CIE, en su edición vigente. En los hospitales ese certificado es expedido por el médico tratante; en el curso de una epidemia no es de esperar que ese paso se registre con toda prontitud y diligencia. Cuando la muerte ocurre en casa o en algún otro espacio privado o público, debe acudir un médico (o personal de salud capacitado y autorizado) y certificar la defunción. El segundo paso es presentar el certificado ante la autoridad civil para que esta expida el acta de defunción, documento que es llenado habitualmente (pero no exclusivamente, pues en casos frecuentes el trámite lo hacen los familiares) por personal de las funerarias y tramitado por ellas; el acta sirve para disponer de los restos del difunto. En el acta se asienta la causa de muerte "final" pero no es necesariamente bien asentada, de ahí que la autoridad sanitaria (SSA) y la autoridad estadística (INEGI) cotejen toda la documentación para publicar los datos de mortalidad, proceso que tarda un tiempo considerable (los datos de mortalidad más recientes son de 2018, los de 2019 se tendrán hacia octubre de este año).

Las dos observaciones permiten argumentar que las cifras "ocultas" son, en efecto, el resultado de un proceso en el que intervienen muchos profesionales y se da en instancias diferentes de la administración pública, nada tienen que ver con el escamoteo de información "para que no se sepa" o cosas por el estilo. Los datos que se publican a diario, ¿cómo podrían echarse para atrás, y qué se ganaría con ello?

En el cuadro 1 se exponen los datos generales de las poblaciones bajo estudio; dichos datos son distintos a los presentados al inicio de esta sección, pues la fecha de referencia es el 17 de julio (la preparación de la redacción del artículo y el procesamiento de la información requiere días o semanas). ¿Habrá cambios importantes o muy notorios 
en los resultados si se tomara una fecha de referencia más reciente? Por lo analizado, lo considero poco probable.

Lo que llama la atención del cuadro 1 en sus tres partes es algo que se ha venido repitiendo: la pandemia ha afectado de manera diferenciada a mujeres de hombres, y a jóvenes de personas adultas mayores. Lo importante es, en primer lugar, que esa diferencia es más notoria en los adultos de 55 años y más, cuya prueba fue positiva a Sars-Cov2, y mucho más grande entre los que fallecieron en ese grupo de edad. Los números son: $22.8 \%$ de adultos de 55 años y más a los que se les hizo prueba confirmatoria, $28.4 \%$ los que resultaron positivos y $69.7 \%$ los que fallecieron. Esta última cifra indica la gravedad de la pandemia para los adultos mayores, y da la primera pista en la comprensión de las características de la pandemia en México. Con respecto al sexo de los afectados y no afectados, los datos muestran una diferencia sistemática de afectación mayor a los hombres en todos los grupos de edad. Se podría suponer que lo anterior se debe a que se hicieron más pruebas a los hombres; sin embargo, la diferencia es muy pequeña: hombres $50.2 \%$, mujeres $49.8 \%$. 
Cuadro 1. Datos generales de las poblaciones en estudio

(Corte al 17 de julio de 2020)

\begin{tabular}{|c|c|c|c|c|c|c|c|c|c|}
\hline \multirow{2}{*}{$\begin{array}{c}\text { Grupo de } \\
\text { edad }\end{array}$} & \multicolumn{3}{|c|}{ Población estudiada } & \multicolumn{3}{|c|}{ Población con Sars-Cov2 } & \multicolumn{3}{|c|}{ Defunciones } \\
\hline & Total & Mujeres & Hombres & Total & Mujeres & Hombres & Total & Mujeres & Hombres \\
\hline & 799.178 & 398.301 & 400.877 & 331.298 & 153,143 & 178,155 & 38,310 & 13,292 & 25,018 \\
\hline & & & & & & & & & \\
\hline $0-4$ & 10,507 & 4,756 & 5,751 & 1,984 & 926 & 1,058 & 70 & 31 & 39 \\
\hline $5-14$ & 15,451 & 7,576 & 7,875 & 3,726 & 1,800 & 1,926 & 38 & 20 & 18 \\
\hline $15-24$ & 62.279 & 32,828 & 29,451 & 19,857 & 10,134 & 9,723 & 181 & 85 & 96 \\
\hline $25-34$ & 186,378 & 96,643 & 89,735 & 67,306 & 33,066 & 34,240 & 1,015 & 315 & 700 \\
\hline $35-44$ & 184,619 & 93,686 & 90,933 & 74,242 & 34,512 & 39,730 & 3,108 & 902 & 2,206 \\
\hline $45-54$ & 157,671 & 79,409 & 78,262 & 70,032 & 32,072 & 37,960 & 7.165 & 2.201 & 4.964 \\
\hline $55-64$ & 98,993 & 46,012 & 52,981 & 49,470 & 21,506 & 27,964 & 10,195 & 3,492 & 6,703 \\
\hline $65-74$ & 50,954 & 22,455 & 28,499 & 28,041 & 11,886 & 16,155 & 9,516 & 3,471 & 6,045 \\
\hline $75-84$ & 24,337 & 10,942 & 13,395 & 12,938 & 5,558 & 7,380 & 5,419 & 2,136 & 3,283 \\
\hline $84->$ & 7,989 & 3,994 & 3,995 & 3,702 & 1,683 & 2,019 & 1,603 & 639 & 964 \\
\hline & & & & & & & & & \\
\hline \multicolumn{10}{|c|}{ Porcentajes por columna } \\
\hline & \multirow{2}{*}{\multicolumn{3}{|c|}{ Población estudiada }} & \multirow{2}{*}{\multicolumn{3}{|c|}{ Población con Sars-Cov2 }} & \multirow{2}{*}{\multicolumn{3}{|c|}{ Defunciones }} \\
\hline \multirow{2}{*}{$\begin{array}{c}\text { Grupo de } \\
\text { edad }\end{array}$} & & & & & & & & & \\
\hline & Total & Mujeres & Hombres & Total & Mujeres & Hombres & Total & Mujeres & Hombres \\
\hline & & & & & & & & & \\
\hline & 100.0 & 100.0 & 100.0 & 100.0 & 100.0 & 100.0 & 100.0 & 100.0 & 100.0 \\
\hline & & & & & & & & & \\
\hline $0-4$ & 1.3 & 1.2 & 1.4 & 0.6 & 0.6 & 0.6 & 0.2 & 0.2 & 0.2 \\
\hline $5-14$ & 1.9 & 1.9 & 2.0 & 1.1 & 1.2 & 1.1 & 0.1 & 0.2 & 0.1 \\
\hline $15-24$ & 7.8 & 8.2 & 7.3 & 6.0 & 6.6 & 5.5 & 0.5 & 0.6 & 0.4 \\
\hline $25-34$ & 23.3 & 24.3 & 22.4 & 20.3 & 21.6 & 19.2 & 2.6 & 2.4 & 2.8 \\
\hline $35-44$ & 23.1 & 23.5 & 22.7 & 22.4 & 22.5 & 22.3 & 8.1 & 6.8 & 8.8 \\
\hline $45-54$ & 19.7 & 19.9 & 19.5 & 21.1 & 20.9 & 21.3 & 18.7 & 16.6 & 19.8 \\
\hline $55-64$ & 12.4 & 11.6 & 13.2 & 14.9 & 14.0 & 15.7 & 26.6 & 26.3 & 26.8 \\
\hline $65-74$ & 6.4 & 5.6 & 7.1 & 8.5 & 7.8 & 9.1 & 24.8 & 26.1 & 24.2 \\
\hline $75-84$ & 3.0 & 2.7 & 3.3 & 3.9 & 3.6 & 4.1 & 14.1 & 16.1 & 13.1 \\
\hline 84-> & 1.0 & 1.0 & 1.0 & 1.1 & 1.1 & 1.1 & 4.2 & 4.8 & 3.9 \\
\hline & & & & & & & & & \\
\hline \multicolumn{10}{|c|}{ Porcentajes por renglón } \\
\hline \multirow{3}{*}{$\begin{array}{c}\text { Grupo de } \\
\text { edad }\end{array}$} & \multicolumn{3}{|c|}{ Población estudiada } & \multicolumn{3}{|c|}{ Población con Sars-Cov2 } & \multicolumn{3}{|c|}{ Defunciones } \\
\hline & Total & Mujeres & Hombres & Total & Mujeres & Hombres & Total & Mujeres & Hombres \\
\hline & 100.0 & 49.8 & 50.2 & 100.0 & 46.2 & 53.8 & 100.0 & 34.7 & 65.3 \\
\hline & & & & & & & & & \\
\hline $0-4$ & 100.0 & 45.3 & 54.7 & 100.0 & 46.7 & 53.3 & 100.0 & 44.3 & 55.7 \\
\hline 5-14 & 100.0 & 49.0 & 51.0 & 100.0 & 48.3 & 51.7 & 100.0 & 52.6 & 47.4 \\
\hline $15-24$ & 100.0 & 52.7 & 47.3 & 100.0 & 51.0 & 49.0 & 100.0 & 47.0 & 53.0 \\
\hline $25-34$ & 100.0 & 51.9 & 48.1 & 100.0 & 49.1 & 50.9 & 100.0 & 31.0 & 69.0 \\
\hline $35-44$ & 100.0 & 50.7 & 49.3 & 100.0 & 46.5 & 53.5 & 100.0 & 29.0 & 71.0 \\
\hline $45-54$ & 100.0 & 50.4 & 49.6 & 100.0 & 45.8 & 54.2 & 100.0 & 30.7 & 69.3 \\
\hline $55-64$ & 100.0 & 46.5 & 53.5 & 100.0 & 43.5 & 56.5 & 100.0 & 34.3 & 65.7 \\
\hline $65-74$ & 100.0 & 44.1 & 55.9 & 100.0 & 42.4 & 57.6 & 100.0 & 36.5 & 63.5 \\
\hline $75-84$ & 100.0 & 45.0 & 55.0 & 100.0 & 43.0 & 57.0 & 100.0 & 39.4 & 60.6 \\
\hline $84->$ & 100.0 & 50.0 & 50.0 & 100.0 & 45.5 & 54.5 & 100.0 & 39.9 & 60.1 \\
\hline
\end{tabular}

La letalidad del síndrome es alta, bajo el supuesto de que el número de pruebas es muy bajo, pues, efectivamente, si el denominador es más grande, el resultado es menor; por eso en los países en los que se tomó la decisión de realizar pruebas masivas los índices de letalidad son más bajos.

Hay que enfatizar, sin embargo, que en la tasa de letalidad cuenta no solo el denominador de la fórmula (en este 
caso el número de casos positivos confirmados), sino también su efecto en el numerador, pues este es una fracción de aquel (en este caso las defunciones confirmadas); es decir, existe mayor probabilidad de que haya más defunciones al incrementarse el número de casos, aunque, debido a un gran número de factores -infraestructura de salud, calidad y oportunidad de la atención médica y en general de los servicios, pero, sobre todo, la condición de salud de los pacientes previa al contagio-, la letalidad puede ser mayor o menor. También influye en su cálculo, de manera fundamental, la fase en la que se encuentre la epidemia, y en México (y se podría generalizar) aún falta para que su control sea seguro para las personas (en términos técnicos, para que el factor de reproducción de los contagios $\mathrm{R}$ disminuya a menos de 1 ). No se sabe, entonces, con certeza cuál será el curso mediato y, por tanto, los datos de letalidad deben ser tomados como provisionales. Por grupos de edad y sexo, la letalidad se presenta de la siguiente manera (cuadro 2):

Cuadro 2. Tasas de letalidad por grupos de edad y sexo

\begin{tabular}{|c|c|c|c|}
\hline \multirow{2}{*}{$\begin{array}{c}\text { Grupos de } \\
\text { edad }\end{array}$} & \multicolumn{3}{|c|}{ Letalidad } \\
\hline & Total & Mujeres & Hombres \\
\hline Total & 11.6 & 8.7 & 14.0 \\
\hline $0-4$ & 3.5 & 3.8 & 4.3 \\
\hline $5-14$ & 1.0 & 1.1 & 0.9 \\
\hline $15-24$ & 0.9 & 0.9 & 1.0 \\
\hline $25-34$ & 1.5 & 1.0 & 2.2 \\
\hline $35-44$ & 4.2 & 2.8 & 5.9 \\
\hline $45-54$ & 10.2 & 7.1 & 13.5 \\
\hline $55-64$ & 20.6 & 16.6 & 24.4 \\
\hline $65-74$ & 33.9 & 29.8 & 37.8 \\
\hline $75-84$ & 41.9 & 39.6 & 44.7 \\
\hline $84->$ & 43.3 & 37.5 & 47.0 \\
\hline
\end{tabular}


Es claro que la afectación entre quienes han fallecido se encuentra en su condición de ser hombre o mujer y en ser joven o adulto. La probabilidad de morir es alta, en general, si se tiene más edad. También es mayor la susceptibilidad al contagio y a la presentación de síntomas y efectos graves de la enfermedad. Como se argumentará más adelante, existían condiciones de salud precarias antes de la pandemia que reforzaron aquella vulnerabilidad.

Gráfica 2. La pandemia por entidades federativas

(Tasas de positividad y de letalidad)

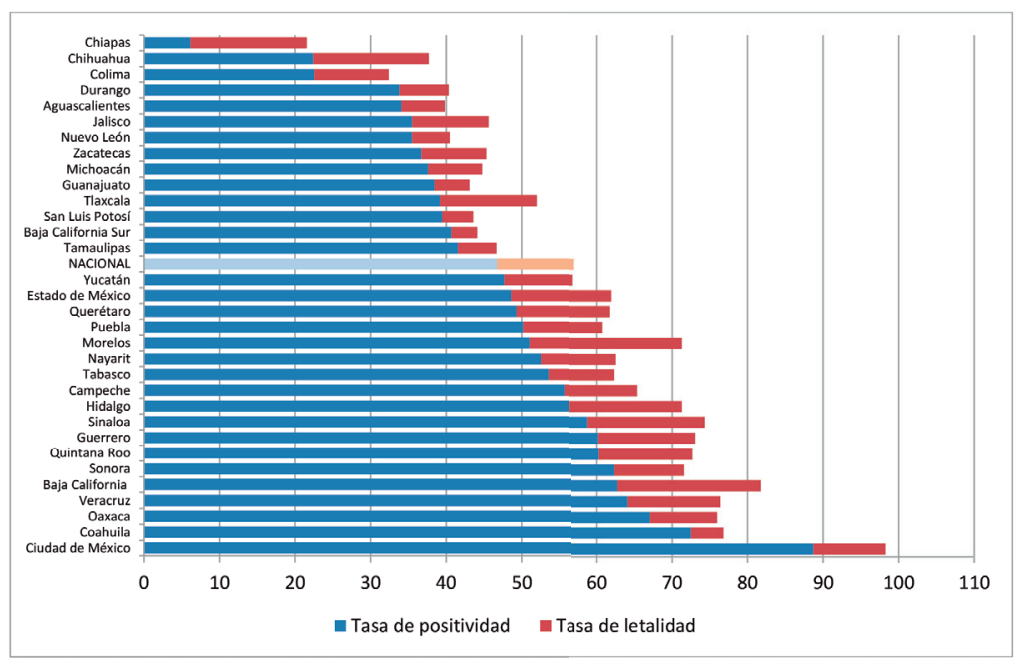

Otro aspecto sobre el que sería preciso realizar un estudio detallado (aquí solo se presenta una brevísima aproximación) se refiere a las diferencias espaciales y demográficas de la pandemia en un país marcado fuertemente por ellas; la respuesta al contagio y sus efectos delimita una epidemia dispersa, dividida en espacios heterogéneos y en poblaciones distintas. Las diferencias son también políticas, económi- 
cas, ambientales, culturales. Cada factor contribuye en la configuración de una epidemia "diferente".

La gráfica 2 muestra esas diferencias en las dos variables fundamentales del curso de la epidemia: los casos positivos y las defunciones. No hay un patrón discernible con el que pueda sostenerse la idea de que a mayor número de pruebas menor letalidad, o viceversa. Baste observar tres casos: la Ciudad de México, Morelos y Chiapas: en la primera se han realizado 81,087 pruebas, con una positividad de $88.7 \%$ y una letalidad de $9.5 \%$, mientras que en el segundo se han hecho 7,660 pruebas con una positividad de $51.0 \%$ y una tasa de letalidad de 20.3\%. En Chiapas se han realizado 94,051 pruebas, con una positividad de solo $6.1 \%$ y $15.4 \%$ de letalidad.

Las diferencias se encuentran, entonces, en otro lugar. Factiblemente, en el descuido o abandono en el que se dejó a las instituciones públicas de salud y en un proceso paralelo o sustitutivo, al fomentar la creación de un "mercado" para la salud de la población sin seguridad social e incentivar (así haya sido como "efecto perverso" de la política pública) la "desigualdad vertical" creando una institución de salud para los pobres, con servicios incompletos y dotación estandarizada de estos. El cuadro 3 puede servir de ilustración: 
La pandemia de la CoviD-19 en México y la otra epidemia

Cuadro 3. Recursos y servicios para la salud

(indicadores seleccionados)

\begin{tabular}{|c|c|c|c|c|c|}
\hline Indicadores & 1980 & 1990 & 2000 & 2010 & 2018 \\
\hline POBLACIÓN & $66,846,833$ & $84,169,571$ & $98,785,275$ & $113,748,671$ & $125,327,797$ \\
\hline \multicolumn{6}{|c|}{ RECURSOS } \\
\hline $\begin{array}{l}\text { Unidades de atención (total de } \\
\text { unidades por } 100 \text { mil habitantes) }\end{array}$ & 8.9 & 14.6 & 18.0 & 19.2 & 18.0 \\
\hline Unidades de consulta externa & 8.2 & 13.6 & 16.8 & 18.1 & 16.9 \\
\hline Unidades de hospitalización & 0.7 & 1.0 & 1.2 & 1.1 & 1.1 \\
\hline Camas (por mil habitantes) & 0.73 & 0.74 & 0.78 & 0.78 & 0.71 \\
\hline Consultorios (por mil habitantes) & 0.2 & 0.4 & 0.5 & 0.6 & 0.6 \\
\hline Médicos (por mil habitantes) & 0.9 & 1.0 & 1.4 & 1.5 & 1.8 \\
\hline Enfermeras (por mil habitantes) & 1.5 & 1.5 & 1.9 & 2.3 & 2.5 \\
\hline \multicolumn{6}{|c|}{ SERVICIOS } \\
\hline \multicolumn{6}{|l|}{ Consulta (por mil habitantes) } \\
\hline Total & 1.3 & 1.7 & 2.4 & 2.7 & 2.5 \\
\hline General & ND & 1.2 & 1.6 & 1.8 & 1.6 \\
\hline Especializada & ND & 0.2 & 0.4 & 0.4 & 0.4 \\
\hline Otras & ND & 0.3 & 0.3 & 0.4 & 0.4 \\
\hline $\begin{array}{l}\text { Egresos hospitalarios (por mil } \\
\text { habitantes) }\end{array}$ & ND & 38.5 & 43.8 & 49.5 & 44.6 \\
\hline $\begin{array}{l}\text { Intervenciones quirúrgicas (por } \\
\text { millón de habitantes) }\end{array}$ & ND & 20.6 & 27.9 & 30.5 & 26.6 \\
\hline
\end{tabular}

$\mathrm{Al}$ analizar cuidadosamente este cuadro se destaca, sobre todo, el estancamiento durante cuatro décadas de la mayoría de los indicadores, señaladamente de los recursos para la salud, como unidades de atención, camas y consultorios y, palmariamente, en los incrementos apenas perceptibles de la cantidad de médicos.

Descuido de décadas. El pensamiento neoliberal, desde los años setenta, difundió la idea de que el Estado de bienestar no era sostenible, porque los recursos eran escasos y las necesidades crecientes; se hizo espacio a la práctica monstruosa de cancelar hasta donde se pudiera los servicios públicos, que eran eliminados o "transferidos" a la inversión privada: "el gobierno es el problema" de Ronald Reagan o 
"la sociedad no existe" de Margaret Thatcher (podría bromearse con otra frase "por qué a mí" del Papa Beato Juan Pablo II), se constituyeron como los lemas fundamentales del neoliberalismo político y fueron guía para las reformas que desde 1982 se hicieron en México.

El proceso de "implantación” de instituciones públicas autónomas, fundamental paso para el sostenimiento de un nuevo perfil de país (además de una exigencia coercitiva de las instituciones internacionales de financiamiento y fomento económico, y no por simple ejecución de líneas geopolíticas impuestas) se hizo bajo la idea de "contrapesar" al Estado, cuando en realidad lo que se creó fue un contrapeso a las atribuciones del poder ejecutivo. El desmantelamiento del precario Estado de bienestar a la mexicana no se inició con las instituciones de salud o de educación o de trabajo, porque no había con que sustituirlas, de modo que ese proceso fue más lento para ellas.

No hay espacio aquí para las comparaciones internacionales, pero el lector interesado puede consultar un estudio reciente de la OCDE y el Banco Mundial (apenas del 16 de junio de 2020) sobre la salud en América Latina y el Caribe. ${ }^{4}$ Baste un dato (cuadro 6.1, p. 139) para sostener que México no sale bien parado: el gasto de gobierno en salud per capita de México es de 585.80 y en Cuba de 2,223.36 (USD/PPA), una diferencia de 1,345.98 dólares menos. El porcentaje de gasto de gobierno vs gasto voluntario de bolsillo es importante: en Uruguay la proporción fue de 70.8 us 29.2 y en México de 51.5 vs 48.5 .

Hasta donde sabemos con certidumbre, ningún país del mundo estaba preparado para una epidemia de un agente altamente contagioso con agravamiento en muchos de los casos de tal forma que se requerirían servicios de hospitalización especializados, con la excepción quizás, de Alemania 
y China (no es posible olvidar la proeza de montar un hospital con toda la estructura requerida de mil camas en diez días; en México se registró que en 2018 había 1,385 unidades de hospitalización -64.3 camas por UH, en promedio- en todas las instituciones públicas de salud).

\section{La otra epidemia}

En México corre de forma paralela a la Covid-19 otra epidemia que ha estado gestándose desde los años 60 del siglo $\mathrm{xx}$, pero que ha tenido un crecimiento inusitado a partir de los años 80. La atención a ella ha sido limitada, coartada y simulada por múltiples medios de poder y de dinero, pero sus efectos saturan los servicios de salud, incrementan los costos de la atención médica de manera exponencial y limitan la capacidad presupuestaria - ya de por sí exiguade las instituciones públicas de salud, y para quienes no tienen acceso ellas produce "gastos catastróficos" de bolsillo (más bien, las familias y los individuos quedan en la ruina permanente). 
Cuadro 4. Comparación de co-morbilidades con COVID-19

\begin{tabular}{|l|c|c|c|}
\hline \multicolumn{1}{|c|}{ Co-morbilidad } & Total & Mujeres & Hombres \\
\hline ENSANUT 2018 & & & \\
\hline Diabetes & 20.5 & 11.4 & 9.1 \\
\hline Hipertensión & 36.2 & 20.9 & 15.3 \\
\hline Obesidad & 36.1 & 27.9 & 23.0 \\
\hline Sobrepeso & 39.1 & 36.6 & 42.5 \\
\hline Positivos a SarsCov2 & & & \\
\hline Diabetes & 16.7 & 16.5 & 16.9 \\
\hline Hipertensión & 20.6 & 20.9 & 20.3 \\
\hline Obesidad & 19.6 & 20.6 & 18.7 \\
\hline Defunciones & & & \\
\hline Diabetes & 37.3 & 43.3 & 34.1 \\
\hline Hipertensión & 42.8 & 50.9 & 38.5 \\
\hline Obesidad & 42.8 & 29.0 & 22.6 \\
\hline
\end{tabular}

La Encuesta Nacional de Salud y Nutrición 2018 (ENSANUT 2018) registró una alta prevalencia de enfermedades y condiciones negativas de salud crónicas, tales como la diabetes, la obesidad y la hipertensión. En la pandemia de COVID-19 han adquirido relevancia en la medida en que se presentan de manera frecuente e insidiosa en quien padece esta enfermedad, tal como se aprecia en el cuadro $4 .^{5}$

5. Los datos son para el grupo de edad de mayores de veinte años. En conjunto, el sobrepeso y la obesidad representan el $75.2 \%$ de ese grupo de edad; su disminución es un verdadero reto de salud pública, cultural y, de manera relevante, en sentido contrario, de interés económico. 
Gráfica 3. Evolución de la mortalidad y la letalidad por diabetes

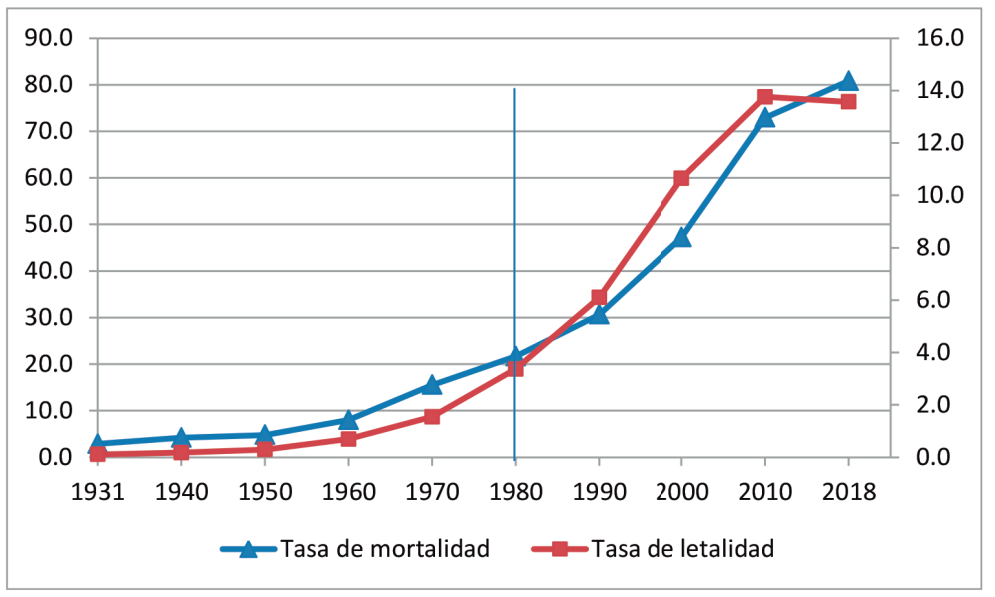

La otra epidemia se empalma con CovID-19 y produce un efecto mortal en una alta proporción de individuos contagiados; también, de hecho, en el caso de la diabetes es condición de contagio.

Desde hace años se sabe que la diabetes es una enfermedad multifactorial que produce diversos estados nocivos que precarizan a mediano y a largo plazos la condición general de salud en los individuos afectados, y que frecuentemente los lleva a la muerte por las complicaciones clínicas que se acumulan y superponen (retinopatía, hipertensión, nefropatía, demencia, problemas vasculares y cardíacos, desequilibrio hormonal, osteoporosis, etcétera), y puede producir invalidez (ceguera, amputaciones, etcétera).

La gráfica $3^{6}$ presenta la evolución de la epidemia de diabetes en México. El segmento de la curva en el cual se aprecia un crecimiento leve es a partir de 1960, pero a partir de 1980 la curva se hace pronunciada hacia arriba. Bastaron veinte años para que la dieta tradicional de los

6. La población base para los cálculos de 1931 fue tomada del Censo de 1930. 
mexicanos cambiara en las zonas urbanas y se incorporará a ella diversos productos de bajo valor nutricional pero presentados como "alimentos nutritivos" por la propaganda creciente en los medios audiovisuales, para entonces en plena expansión. La televisión, en particular, originó una subcultura de alimentación de productos recreacionales, por así decir, como golosinas, refrescos, alimentos ultraprocesados con mucha grasa, sal, azúcar y otros endulzantes, saborizantes, odorizantes y preservativos que, en conjunto, son una "bomba" instantánea por su fácil consumición y adicción, y una "bomba" de tiempo a largo plazo, pues se producen efectos orgánicos indeseables. ¿La dieta de los mexicanos era equilibrada y nutritiva? La respuesta es no. Además había una gran precariedad alimentaria en una proporción muy alta de la población, y el hambre acechaba principalmente a los sectores rurales muy pobres y también a las poblaciones suburbanas crecientes por los fenómenos migratorios campo-ciudad.

Pero la puesta en práctica de políticas restrictivas de gasto para acrecentar la infraestructura de servicios y para solventar de manera permanente las graves carencias de una muy alta proporción de población pobre reforzó el círculo intergeneracional de la pobreza. Durante las décadas de los 80 y 90 , el desmantelamiento de instituciones y acciones dirigidas a contrarrestar permanentemente los efectos del subdesarrollo, a cambio de otras beneficiarias de mercados emergentes, o más bien improvisados, dio pauta a un empobrecimiento mayor y a un incremento de las desigualdades sociales y económicas. Una institución que fue desmontada (liquidada formalmente en 1999, pero transformada desde 1993) sin ninguna alternativa fue CONASUPO (Compañía Nacional de Subsistencias Populares), medida que incluso el Banco Mundial vio como exagerada, y una acción directa sobre la alimentación infantil fue progresivamente minimizada: la distribución gratuita o casi gratuita de desayunos 
escolares. Esta corroboración por medio de ejemplos podría ampliarse. Hay material abundante bibliográfico, hemerográfico y académico, además de interpretaciones variadas de los efectos negativos de las políticas neoliberales. ${ }^{7} \mathrm{Se}$ hizo añicos la posibilidad de que la dieta nacional mejorara y de que la seguridad alimentaria fuera un propósito claro, refrendado en la práctica. ${ }^{8}$ Para una perspectiva individualista, el hecho de que haya sobrepeso, obesidad, diabetes o hipertensión tiene como fundamento último la decisión de cada persona. Esta visión carga en la persona común y corriente el peso completo de sus problemas de salud, y omite que en la sociedad urbana los individuos no producen sus alimentos y se ven coaccionados a adquirirlos en un mercado amplificado y oligopolizado de oferta de alimentos recreativos (o "chatarra", como se dice popularmente). Lo anterior no significa que se dejen de consumir los alimentos tradicionales, ni que todos ellos sean inocuos para la salud, lo que se quiere reafirmar es que esos alimentos recreativos se suman a todo lo demás que las personas consumen, lo cual produce en ellos enfermedad a largo plazo.

La pandemia de la Covid-19 en México desenmascaró crudamente la participación de esas condiciones y enfermedades - diabetes, hipertensión, obesidad-como comorbilidades en el riesgo de contraer la enfermedad causada por el coronavirus Sars-Cov2, y de morir por el incremento de las complicaciones y la severidad con que ataca a los individuos debilitados y vulnerables. En el cuadro 5 se da un resumen del impacto de esas comorbilidades:

7.Ver, entre otros estudios:José Luis Ávila (2006). La era neoliberal.Tomo 6. Historia económica de México. Enrique Semo (Coord.). Océano/unam, México. Hay edición electrónica de 2014. Un artículo reciente:José Luis Calva."La economía mexicana en su laberinto neoliberal”, El trimestre económico, vol. LXXXVI (3), núm. 343, julioseptiembre de 2019, pp. 579-622.

8. La ENSANUT 2018 refiere que alrededor del $20.6 \%$ de los hogares urbanos padece de inseguridad alimentaria de moderada a grave, mientras que ese porcentaje es del 28.9 para los hogares rurales. 
Cuadro 5. Comorbilidades en los confirmados positivos y en las defunciones

\begin{tabular}{|l|r|r|r|r|r|r|r|}
\hline \multirow{2}{*}{ Co-morbilidad } & \multicolumn{3}{|c|}{ Positivos a SarsCov2 } & \multicolumn{3}{|c|}{ Defunciones } \\
\cline { 2 - 8 } & \multicolumn{1}{c|}{ Total } & \multicolumn{1}{c|}{ Mujeres } & \multicolumn{1}{c|}{ Hombres } & \multicolumn{1}{c|}{ Total } & Mujeres & Hombres \\
\hline & 331,298 & 153,143 & 178,155 & 38,310 & 13,292 & 25,018 \\
\hline Diabetes & 53,712 & 24,518 & 29,194 & 14,295 & 5,755 & 8,540 \\
\hline Hipertensión & 66,170 & 30,962 & 35,208 & 16,409 & 6,767 & 9,642 \\
\hline Obesidad & 63,459 & 30,808 & 32,651 & 9,504 & 3,858 & 5,646 \\
\hline Diabetes \% & 16.2 & 16.0 & 16.4 & 37.3 & 43.3 & 34.1 \\
\hline Hipertensión \% & 20.0 & 20.2 & 19.8 & 42.8 & 50.9 & 38.5 \\
\hline Obesidad \% & 19.2 & 20.1 & 18.3 & 24.8 & 29.0 & 22.6 \\
\hline
\end{tabular}

Los datos para diabetes son significativos en el contagio y el desenlace de la enfermedad por Covid-19 en los individuos que padecen esa enfermedad, pues son más altos de los que registra la ENSANUT 2018; en el caso de la hipertensión, los datos se corresponden con los descritos en dicha encuesta, mientras que los de obesidad son más bajos, asunto que sería necesario investigar a fondo.

Las comorbilidades implican un alto riesgo de morir para quien se ha contagiado con Sars-Cov2 y ha desarrollado con gravedad la enfermedad de la Covid-19. Al analizar con mayor detalle los datos disponibles se encuentra que la proporción de defunciones es más grande en los individuos que tienen una enfermedad previa; ese pormenor se puede observar en el cuadro 6 . 
La pandemia de la CoviD-19 en México y la otra epidemia

Cuadro 6. Impacto de las comorbilidades combinadas en las defunciones por COVID-19 (por sexo y grupo de edad)

\begin{tabular}{|c|c|c|c|c|c|c|c|c|c|}
\hline Co-Morbilidades & Total & Mujeres & Hombres & Total & Mujeres & Hombres & Mujeres & Hombres & \begin{tabular}{|c|}
$\begin{array}{c}\text { Hombres / } \\
\text { Mujeres }\end{array}$ \\
\end{tabular} \\
\hline Total & 38,310 & 13,292 & 25,018 & 100.0 & 100.0 & 100.0 & 34.7 & 65.3 & 1.9 \\
\hline & & & & & & & & & \\
\hline Diabetes/Hipertensión/Obesidad & 2,690 & 1,345 & 1,345 & 7.0 & 10.1 & 5.4 & 50.0 & 50.0 & 1.0 \\
\hline Diabetes e Hipertensión & 6,215 & 2,519 & 3,696 & 16.2 & 19.0 & 14.8 & 40.5 & 59.5 & 1.5 \\
\hline Diabetes y Obesidad & 1,203 & 504 & 699 & 3.1 & 3.8 & 2.8 & 41.9 & 58.1 & 1.4 \\
\hline Hipertensión y Obesidad & 4,187 & 1,387 & 2,800 & 10.9 & 10.4 & 11.2 & 33.1 & 66.9 & 2.0 \\
\hline Diabetes & 2,165 & 947 & 1,218 & 5.7 & 7.1 & 4.9 & 43.7 & 56.3 & 1.3 \\
\hline Hipertensión & 5,339 & 1,956 & 3,383 & 13.9 & 14.7 & 13.5 & 36.6 & 63.4 & 1.7 \\
\hline Obesidad & 3,446 & 1,062 & 2,384 & 9.0 & 8.0 & 9.5 & 30.8 & 69.2 & 2.2 \\
\hline Sin Co-morbilidad & 12,829 & 3,513 & 9,316 & 33.5 & 26.4 & 37.2 & 27.4 & 72.6 & 2.7 \\
\hline Se ignora & 236 & 59 & 177 & 0.6 & 0.4 & 0.7 & 25.0 & 75.0 & 3.0 \\
\hline Grupo de edad de 0 a 54 años & 11,577 & 3,568 & 8,055 & 30.2 & 26.8 & 32.2 & 30.8 & 69.6 & 2.3 \\
\hline & & & & & & & & & \\
\hline Diabetes/Hipertensión/Obesidad & 680 & 297 & 383 & 1.8 & 2.2 & 1.5 & 43.7 & 56.3 & 1.3 \\
\hline Diabetes e Hipertensión & 1,075 & 423 & 656 & 2.8 & 3.2 & 2.6 & 39.3 & 61.0 & 1.6 \\
\hline Diabetes y Obesidad & 467 & 164 & 304 & 1.2 & 1.2 & 1.2 & 35.1 & 65.1 & 1.9 \\
\hline Hipertensión y Obesidad & 1,181 & 394 & 805 & 3.1 & 3.0 & 3.2 & 33.4 & 68.2 & 2.0 \\
\hline Diabetes & 666 & 216 & 450 & 1.7 & 1.6 & 1.8 & 32.4 & 67.6 & 2.1 \\
\hline Hipertensión & 915 & 303 & 620 & 2.4 & 2.3 & 2.5 & 33.1 & 67.8 & 2.0 \\
\hline Obesidad & 1,869 & 526 & 1,358 & 4.9 & 4.0 & 5.4 & 28.1 & 72.7 & 2.6 \\
\hline Sin Co-morbilidad & 4,585 & 1,210 & 3,375 & 12.0 & 9.1 & 13.5 & 26.4 & 73.6 & 2.8 \\
\hline Se ignora & 139 & 35 & 104 & 0.4 & 0.3 & 0.4 & 25.2 & 74.8 & 3.0 \\
\hline Grupo de edad > de 55 años & 26,733 & 9,724 & 16,963 & 69.8 & 73.2 & 67.8 & 36.4 & 63.5 & 1.7 \\
\hline & & & & & & & & & \\
\hline Diabetes/Hipertensión/Obesidad & 2,010 & 1,048 & 962 & 5.2 & 7.9 & 3.8 & 52.1 & 47.9 & 0.9 \\
\hline Diabetes e Hipertensión & 5,140 & 2,096 & 3,040 & 13.4 & 15.8 & 12.2 & 40.8 & 59.1 & 1.5 \\
\hline Diabetes y Obesidad & 736 & 340 & 395 & 1.9 & 2.6 & 1.6 & 46.2 & 53.7 & 1.2 \\
\hline Hipertensión y Obesidad & 3,006 & 993 & 1,995 & 7.8 & 7.5 & 8.0 & 33.0 & 66.4 & 2.0 \\
\hline Diabetes & 1,499 & 731 & 768 & 3.9 & 5.5 & 3.1 & 48.8 & 51.2 & 1.1 \\
\hline Hipertensión & 4,424 & 1,653 & 2,763 & 11.5 & 12.4 & 11.0 & 37.4 & 62.5 & 1.7 \\
\hline Obesidad & 1,577 & 536 & 1,026 & 4.1 & 4.0 & 4.1 & 34.0 & 65.1 & 1.9 \\
\hline Sin Co-morbilidad & 8,244 & 2,303 & 5,941 & 21.5 & 17.3 & 23.7 & 27.9 & 72.1 & 2.6 \\
\hline Se ignora & 97 & 24 & 73 & 0.3 & 0.2 & 0.3 & 24.7 & 75.3 & 3.0 \\
\hline
\end{tabular}

En conjunto, el porcentaje de defunciones por CoviD-19 en el grupo de edad de 55 años y más es enorme: $69.8 \%$ en total, $73 \%$ para las mujeres y $67.8 \%$ para los hombres. Los porcentajes respectivos para los que padecían una comorbilidad o más son: $48 \%$ total, $55.7 \%$ mujeres y $43.8 \%$ hombres. La diferencia entre sexos es también palmaria, pues en todos los casos el porcentaje de hombres es mayor, excepto en la combinación de tres comorbilidades, que es ligeramente menor en el grupo de edad de los adultos mayores de 54 años.

Es importante discernir el impacto de las comorbilidades en la letalidad (provisional) observada. Excepto en la obesidad sola, las tasas de letalidad son mayores que las tasas generales por sexo, que en el caso de la combinación 
diabetes e hipertensión es 2.75 veces más grande que la tasa general. Los datos puntuales aparecen en el cuadro 7.

Cuadro 7. Tasas de letalidad según comorbilidad y sexo

\begin{tabular}{|l|c|c|c|}
\hline \multicolumn{1}{|c|}{ Co-morbilidad } & Total & Mujeres & Hombres \\
\hline & 11.6 & 8.7 & 5.2 \\
\hline Diabetes/Hipertensión/Obesidad & 29.0 & 26.9 & 9.4 \\
\hline Diabetes e Hipertensión & 31.9 & 28.4 & 13.0 \\
\hline Diabetes y Obesidad & 20.4 & 17.4 & 7.9 \\
\hline Hipertensión y Obesidad & 22.0 & 17.9 & 10.5 \\
\hline Diabetes & 19.2 & 17.4 & 7.3 \\
\hline Hipertensión & 20.5 & 16.8 & 9.0 \\
\hline Obesidad & 9.3 & 6.1 & 4.4 \\
\hline Sin Co-morbilidad & 6.3 & 3.8 & 3.2 \\
\hline
\end{tabular}

De lo dicho hasta aquí queda claro que la probabilidad de morir si se combinan diversas condiciones clínicas previas al contagio es alta, más si se consideran otras enfermedades que pueden ser, incluso, concomitantes a una de las afecciones descritas. Entre las enfermedades exploradas a quienes tienen el infortunio de ser contagiados por SarsCov2 y desarrollar covid-19 que exija hospitalización del paciente se destacan: enfermedad pulmonar obstructiva crónica (EPOC), asma, enfermedades del corazón, insuficiencia renal, inmunosupresión y otras que contribuyen a agravar la condición de los pacientes y a producir desenlaces letales.

Una alta proporción de pacientes con CoviD-19 desarrolla neumonía, y una fracción de este subconjunto necesita intubación para preservar la vida. Es evidente que hay una proporción de pacientes que no logra sobrevivir, incluso con una atención oportuna y eficiente, por los escasos elementos con que se cuenta para combatir esta insidiosa enfermedad. 
Esta condición de enfermedad, quizás con características indeseables por su resistencia a los tratamientos habituales, sea porque su desarrollo es rápido, intenso y contundente, sea porque el diagnóstico y la atención no sean oportunos, u otras condicionantes, da como resultado frecuente la muerte del paciente. De tal forma que la neumonía debe estudiarse en conjunto con las comorbilidades para saber si están relacionadas y, en cualquier caso, si tiene esa asociación un riesgo y probabilidad mayores de que, siendo el paciente diabético, hipertenso u obeso, se desarrolle neumonía. Dada la provisionalidad de los datos disponibles y su eventual desarrollo a otras posibles explicaciones, es improcedente, desde mi punto de vista, tratar de modelar con técnicas muy sofisticadas esas relaciones. Otra posibilidad es la siguiente (cuadro 8):

Cuadro 8. Asociación de comorbilidades con neumonía

\begin{tabular}{|l|c|c|c|}
\hline \multirow{2}{*}{ Asociación } & \multicolumn{3}{|c|}{ Co-morbilidades } \\
\cline { 2 - 4 } & Diabetes & Hipertensión & Obesidad \\
\hline Positivos con neumonía & 22,729 & 25,151 & 17,959 \\
\hline con co-morbilidad & $(31.3 \%)$ & $(34.6 \%)$ & $(24.7 \%)$ \\
\hline $\boldsymbol{p}$ & 0.000000 & 0.000000 & 0.000000 \\
\hline RM & 3.36 & 2.68 & 1.54 \\
\hline \multicolumn{1}{|c|}{ Inferior } & 3.29 & 2.63 & 1.51 \\
\hline \multicolumn{1}{|c|}{ Superior } & 3.42 & 2.73 & 1.52 \\
\hline RR & 2.36 & 2.04 & 1.50 \\
\hline \multicolumn{1}{|l}{ Inferior } & 2.33 & 1.37 & 1.49 \\
\hline \multicolumn{1}{|c|}{ Superior } & 2.39 & 2.07 & 1.51 \\
\hline Positivos con neumonía & 28.0 & 31.7 & 19.0 \\
\hline que fallecieron ( \%) & & & \\
\hline
\end{tabular}

Positivos con neumonía $=72,675$.

Defunciones $=38,310$. 
Como se puede observar, la probabilidad de desarrollar neumonía si se padece diabetes siendo positivo a COVID-19 es mayor 3 veces, y, en el caso de la hipertensión, mayor 2.6 veces. En cuanto al riesgo relativo, la conclusión es similar, pues se demuestra una asociación representativa entre el riesgo de padecer neumonía (variable dependiente) con la presencia de una comorbilidad (variables independientes). Por otra parte queda claro que la proporción de enfermos de diabetes, hipertensión y obesidad que desarrollaron neumonía y fallecieron es relativamente alta, tomando en cuenta que dichas afecciones se analizaron por sí solas y no, como ya vimos, en sus combinaciones.

La edad por sí sola es una condición de riesgo, lo mismo que el sexo, como se puede comprobar en el análisis hasta aquí realizado. Por lo mismo, la pregunta más acuciante es, tanto para la población como para las autoridades (y que se constituye como uno de los ejes de este trabajo): ¿Qué probabilidad hay de fallecer a causa de la covid-19 y sus complicaciones si la prueba para Sars-Cov2 resulta positiva? Para tener una o varias respuestas que sean, además de sensatas, aceptables desde la experiencia adquirida en estos intensos meses de evolución de la pandemia, es necesario introducir técnicas y métodos que den una imagen aproximada de lo que ocurre.

Una posibilidad es aplicar métodos numéricos de probabilidad condicional (como los que provee la teoría bayesiana). $\mathrm{Al}$ aplicar un modelo sencillo de esta forma de calcular las probabilidades se encuentran resultados en cualquier caso congruentes con lo ya encontrado por técnicas descriptivas; los resultados aparecen en el cuadro 9 (en un apéndice se encontrará descrito el modelo y sus supuestos: 
Cuadro 9. Probabilidades de fallecer por COVID-19 si la prueba de Sars-Cov2 es positiva

\begin{tabular}{|l|l|l|r|}
\hline \multicolumn{1}{|c|}{ Probabilidad } & \multicolumn{1}{c|}{ Total } & Mujeres & \multicolumn{1}{c|}{ Hombres } \\
\hline P(A/D) Total & & & \\
\hline P(A/D) de menores de 55 años & 0.19624 & 0.14307 & 0.24552 \\
\hline P(A/D) de 55 años y más & 0.08267 & 0.05155 & 0.11347 \\
\hline & & 0.41081 & 0.54167 \\
\hline
\end{tabular}

Los resultados no dejan lugar a dudas: la probabilidad de fallecer es muy grande si se pertenece al grupo de edad de más de 54 años y si se es hombre (52.2\%); pero es también un dato relevante el hecho de que la probabilidad para las mujeres sea igualmente alta (41.1\%). Ante el desconocimiento de muchas personas de su condición de salud real (previa) al contagio - me refiero en particular a la enorme cantidad de personas maduras y adultas que no saben que tienen diabetes o hipertensión-, casi cualquier medida que no sea el confinamiento resulta altamente riesgosa.

La oportunidad de la atención es un factor cuyo control escapa en buena parte a las autoridades sanitarias y a la peculiar presentación de la enfermedad en cada una de las personas. ¿Con qué síntomas y cuándo se debe acudir al hospital? Los datos disponibles dan pistas para saber dar respuesta a esta pregunta. Los síntomas pueden desarrollarse con menor o mayor intensidad y en un orden muchas veces confuso para quienes los padecen. Además, las respuestas a las preguntas sobre fechas de presentación de síntomas no las da siempre el afectado, y pueden confundir al médico tratante y en general al personal de salud que atiende a cada uno de los casos. 
Cuadro 10. Días de estancia de pacientes con COVID-19 según fecha de inicio de síntomas e ingreso a una unidad médica

\begin{tabular}{|c|c|c|c|}
\hline $\begin{array}{c}\text { Días de } \\
\text { estancia en una } \\
\text { UM }\end{array}$ & \multicolumn{2}{|c|}{$\begin{array}{c}\text { Porcentaje de enfermos de Covid-19 que } \\
\text { fallecieron, según fechas relevantes }\end{array}$} \\
\cline { 2 - 4 } & $\begin{array}{c}\text { Fecha de } \\
\text { deceso menos } \\
\text { fecha de inicio } \\
\text { de síntomas }\end{array}$ & $\begin{array}{c}\text { Fecha de } \\
\text { deceso menos } \\
\text { fecha de } \\
\text { ingreso a una } \\
\text { UM }\end{array}$ & $\begin{array}{c}\text { Fecha de } \\
\text { ingreso a una } \\
\text { UM menos } \\
\text { fecha de inicio } \\
\text { de síntomas }\end{array}$ \\
\hline $0-6$ & 25.0 & 54.9 & 75.3 \\
\hline $7-13$ & 41.8 & 28.6 & 22.9 \\
\hline $14-20$ & 21.5 & 10.8 & 1.8 \\
\hline $21-27$ & 7.6 & 3.5 & 0.0 \\
\hline $28-34$ & 2.5 & 1.3 & 0.0 \\
\hline $35>$ & 1.6 & 0.8 & 0.0 \\
\hline Mal clasificado & 0.0 & 0.2 & \\
\hline Promedio & 11.9 & 7.6 & 4.3 \\
\hline Mediana & 10.0 & 6.0 & 4.0 \\
\hline
\end{tabular}

El promedio de días que transcurrieron desde que los pacientes presentaron síntomas hasta su deceso fue de doce (con redondeo), mientras que los días que transcurrieron entre la fecha de ingreso a una unidad médica (UM) y el deceso fue de ocho; del mismo modo, el promedio de días que pasaron entre la presentación de síntomas y el ingreso a una um fue de cuatro. En el cuadro también se puede observar que un alto porcentaje de pacientes (75.3\%) falleció en los primeros seis días desde que comenzaron los síntomas hasta que ingresaron al hospital; también se observa que el 83.5\% de los pacientes fallece en los primeros trece días desde su ingreso a la UM. El 66.8 de los pacientes que murieron había presentado síntomas en los primeros trece días, una fracción de ellos (25\%) presentó síntomas y falleció en los 
primeros seis días. El llamado a no esperar para acudir a una unidad médica, sobre todo si se es mayor de edad y si se conoce la condición de salud, es coherente con las cifras encontradas. La urgencia debe reconocerse cuando hay comorbilidades y condiciones estructurales de los pacientes. La saturación hospitalaria siempre es posible que se dé en casos de epidemias de muy rápida evolución, de ahí que las medidas de distancia social y de confinamiento oportunas permitan "extender" el impacto epidémico en la atención. Las personas con síntomas leves y con alto nivel de riesgo deben acudir con premura a los centros hospitalarios.

¿Cuál es la magnitud de la epidemia en comparación con otras enfermedades? La influenza estacional y otras formas de influenza producida por diversos agentes en conjunto con la neumonía han crecido de manera constante en los últimos veinte años. Y ya se ha hablado aquí de la diabetes como epidemia a largo plazo, de modo que es interesante observar comparativamente el impacto de estos dos padecimientos y la covid-19.

Cuadro 11. Mortalidad y letalidad por causas de muerte

\begin{tabular}{|l|r|r|r|}
\hline \multicolumn{1}{|c|}{ Indicador } & \multicolumn{1}{|c|}{ Diabetes } & $\begin{array}{c}\text { Influenza y } \\
\text { Neumonía }\end{array}$ & \multicolumn{1}{c|}{ Covid-19 } \\
\hline Población & $125,327,797$ & $125,327,797$ & $127,792,286$ \\
\hline Defunciones generales & 722,611 & 722,611 & 331,298 \\
\hline Causa de defunción & 101,257 & 28,332 & 38,310 \\
\hline Mortalidad & 80.79 & 22.61 & 29.98 \\
\hline Letalidad & 14.01 & 3.92 & 11.56 \\
\hline
\end{tabular}

Tasa de mortalidad por 100,000. Tasa de letalidad por 100 . 
Las cifras de población, defunciones y causas de defunción para diabetes, influenza y neumonía son para 2018. La letalidad para COVID-19 está calculada con los casos positivos a Sars-Cov2. Las defunciones totales en 2020 se incrementarán por la covid-19, de modo que no es posible por lo pronto realizar ese cálculo con un grado de aproximación realista.

\section{Una breve reflexión final provisional}

La pandemia de Covid-19 no ha terminado, la otra epidemia tampoco. Cualquier conclusión sobre su evolución y su resolución debe ser provisional y cualquier tentación de afirmaciones taxativas debe dejarse de lado. Tanto la pandemia como la otra epidemia pueden explicarse y comprenderse de modos diversos y complementarios. ¿Todas las opciones interpretativas son válidas y tienen un sentido razonable y no solo argumentable? Mi opinión es que no todas. Las teorías conspirativas, más allá de su bajo nivel de comprobación, están afectadas por el resultado, pues lo cierto es que las personas enferman y mueren de CoviD-19, de manera independiente de si su convicción es que el virus fue producido en un laboratorio ruso o chino o en una base militar norteamericana; o también si no creen en su existencia o sí, pero en realidad todo es un complot para disminuir la población mundial, sobre todo la población pobre, como si el virus fuera quirúrgicamente preciso y clasista.

Hay teorías con bases argumentales sólidas como la de que el capitalismo global, al ser codependiente en sus circuitos mercantiles y al unir territorios en la producción, distribución y consumo de infinitas mercancías, se ha provocado un daño irreparable a sí mismo, y que por tanto las epidemias de agentes que se contagian en el medio social son incontenibles, de tal forma que se convierten en pandemias en un abrir y cerrar de ojos. 
La investigación sobre el origen de los virus es apasionante por sí misma, y las teorías de raíz ecologista que postulan la destrucción del hábitat de las especies silvestres y el contacto con los mercados humanos masivos como causa de esa aparición de nuevos agentes infecciosos son del todo plausibles. Estaríamos entrando en una fase en que la relación animal-humano está desgarrada y sus efectos posibles son de devastación zoonótica y humana. La norma de consumo instituida después de la Segunda Guerra Mundial no incluía solo bienes duraderos, sino también una transformación brutal de los hábitos alimentarios, entre los cuales se encuentra el consumo masivo de productos cárnicos de mamíferos terrestres domesticados, que, en el caso de los bovinos y los cerdos, incrementa el consumo de agua global, pues cada animal necesita una gran cantidad en el trascurso de su vida hasta su sacrificio; también se incrementa la producción de dióxido de carbono, metano y otros contaminantes, etc. Todas estas teorías incrementan nuestro conocimiento (hay otras referidas al crecimiento urbano) y ayudan a comprender el origen de la pandemia. Por otra parte, se han dado explicaciones sobre sus efectos en la vida económica, psíquica, social e incluso política, muy lejos del alcance explicativo de este texto.

El argumento que aquí se presenta - cuánto contribuyen las comorbilidades en la gravedad de la enfermedad que causa el coronavirus Sars-Cov2, y cuál es el riesgo o la probabilidad de morir si se combinan condiciones precisas de morbilidades previas - es limitado en su alcance, pero sus condicionamientos y efectos en la sociedad y la economía son muy amplios, pues se refieren a las normas culturales y sociales de consumo y a la estructura económica que con poder y con dinero quiere mantener el statu quo a como dé lugar.

A los individuos particulares, sumidos en esta coyuntura, habría que recordarles las palabras que Hécate pronuncia en Macbeth, de Shakespeare: "Despreciando el destino, 
se reirá de la muerte, / llevará su esperanza más allá del temor, sabiduría y gracia. / Vosotras lo sabéis: la confianza es para los mortales la peor enemiga".

\section{Apéndice}

\section{Cálculo de probabilidades de Bayes}

¿Qué probabilidad hay de fallecer con covid 19 y sus complicaciones si la prueba para Sars-Cov2 resulta positiva?

\begin{tabular}{|c|c|c|c|c|c|c|c|}
\hline \multirow{2}{*}{ Claves } & \multirow{2}{*}{ Variables } & \multicolumn{3}{|c|}{ Poblaciones } & \multicolumn{3}{|c|}{ Cálculos } \\
\hline & & Total & 0 a 54 años & 55 años $y+$ & Total & $<=55$ & $>=55$ años \\
\hline 1 & Población & 127792386 & 107499941 & 20292345 & & & \\
\hline 2 & Pruebas realizadas & 713,301 & 550,870 & 162,431 & 0.00558 & 0.00512 & 0.00800 \\
\hline 3 & Pruebas negativas & 382,003 & 313,723 & 68,280 & 0.53554 & 0.56950 & 0.42036 \\
\hline 4 & Pruebas positivas & 331,298 & 237,147 & 94,151 & 0.46446 & 0.43050 & 0.57964 \\
\hline 5 & Sobrevivientes & 292,988 & 225,570 & 67,418 & 0.41075 & 0.40948 & 0.41506 \\
\hline 6 & Defunciones & 38,310 & 11,577 & 26,733 & 0.11564 & 0.04882 & 0.28394 \\
\hline
\end{tabular}

Por el teorema de Bayes sabemos que:

Teorema de Bayes

$$
\mathrm{P}(\mathrm{A} / \mathrm{D})=
$$

$\mathrm{P}(\mathrm{D} / \mathrm{A}) * \mathrm{P}(\mathrm{A})$

$\mathrm{P}(\mathrm{D})$

Donde:....

P(A).Pruebas positivas / Pruebas realizadas..4 / 2

P(B).Sobrevivientes / Pruebas positivas..5 / 4

P(D/A) Defunciones / Pruebas positivas...6 / 4

$\mathrm{P}(\mathrm{D} / \mathrm{B})$ Pruebas negativas / Pruebas realizadas..3 / 2

$\mathrm{P}(\mathrm{D})=\mathrm{P}(\mathrm{D} / \mathrm{A}) * \mathrm{P}(\mathrm{A}) /[\mathrm{P}(\mathrm{A}) * \mathrm{P}(\mathrm{D} / \mathrm{A})]+[\mathrm{P}(\mathrm{B}) * \mathrm{P}(\mathrm{D} / \mathrm{B})]$.

Por tanto: 
La pandemia de la CoviD-19 en México y la otra epidemia

\begin{tabular}{|c|c|c|c|}
\hline Probabilidad & Total & 0 a 54 años & 55 años $\mathbf{~ + ~}$ \\
\hline$P(A)$ & 0.46446 & 0.43050 & 0.57964 \\
\hline$P(B)$ & 0.41075 & 0.40948 & 0.41506 \\
\hline$P(D / A)$ & 0.11564 & 0.04882 & 0.28394 \\
\hline$P(D / B)$ & 0.53554 & 0.56950 & 0.42036 \\
\hline$P(A / D)=$ & $\mathbf{0 . 1 9 6 2 4}$ & $\mathbf{0 . 0 8 2 6 7}$ & $\mathbf{0 . 4 8 5 4 1}$ \\
\hline
\end{tabular}

Fuentes de gráficas y cuadros

Gráficas 1a, 1b y 2. Elaboración propia sobre la base de los datos de:

- Secretaría de Salud. Página oficial en línea sobre la epidemia de Sars-Cov2 y covid-19. Los datos corresponden a cuatro archivos en formato CSv Casos Confirmados, Casos Negativos, Defunciones y Casos Sospechosos, con fecha de 22 de julio de 2020. Disponible en: https:// coronavirus.gob.mx.

Gráfica 3. Elaboración propia sobre la base de datos de:

- INEGi. Estadísticas históricas de México, edición de 1994. Archivos electrónicos en formatos pdf y XLXS.

- Secretaría de Salud. DGIS. Base de datos sobre mortalidad. Disponible en: http://www.dgis.salud.gob.mx/ contenidos/basesdedatos/bdc_defunciones_gobmx.html.

Cuadros 1, 2, 5, 6, 7, 8, 9 y 10. Elaboración propia sobre la base de datos de:

- Secretaría de Salud. Página oficial en línea sobre la epidemia de Sars-Cov2 y covid-19. Los datos corresponden a la Base de datos general en formato csv, con fecha de 17 de julio de 2020. Disponible en: https://coronavirus. gob.mx.

Cuadro 3. Elaboración propia basada en:

- INEGi. Estadísticas históricas de México, edición de 1994. Archivos electrónicos en formatos pdf y XLXs. 
- Presidencia de la República. Sexto informe de gobierno 2012. México. Poder Ejecutivo Federal 2012.

- Presidencia de la República. Sexto informe de gobierno 2018. México. Poder Ejecutivo Federal 2018.

- Presidencia de la República. Primer informe de gobierno 2018-2019. México Poder Ejecutivo Federal 2019.

Cuadro 4. Elaboración propia basada en:

- INEGi, INsp y SSA. Encuesta Nacional de Salud y Nutrición 2018 (ENSANut 2018). Presentación de resultados. México 2019.

- Secretaría de Salud. DGis. Base de datos sobre mortalidad. Disponible en: http://www.dgis.salud.gob.mx/ contenidos/basesdedatos/bdc_defunciones_gobmx.html.

Cuadro 11. Elaboración propia basada en:

- Secretaría de Salud. Página oficial en línea sobre la epidemia de Sars-Cov2 y covid-19. Los datos corresponden a la Base de datos general en formato Csv, con fecha de 17 de julio de 2020. Disponible en: https://coronavirus. gob.mx.

- Secretaría de Salud. DGis. Base de datos sobre mortalidad. Disponible en: http://www.dgis.salud.gob.mx/ contenidos/basesdedatos/bdc_defunciones_gobmx.html.

Nota: Los datos sobre población son tomados de: CONAPO. Proyecciones de población. Disponibles en línea: https:// datos.gob.mx/busca/dataset/proyecciones-de-la-poblacion-de-mexico-y-de-las-entidades-federativas-2016-2050.

Bibliografía 298

Ávila, José Luis (2006). La era neoliberal. Tomo 6. Historia económica de México. Enrique Semo (Coord.). México: Océano/UNAM. Hay edición electrónica de 2014.

Calva, José Luis (2019). “La economía mexicana en su laberinto neoliberal”. El Trimestre Económico, vol. LXXXVI (3), núm. 343, julio-septiembre, 579-622. 
Cipolla, Carlo M. (1984). ¿Quién rompió las rejas de Monte Bibliografía Lupo? Barcelona: Muchnik .

(1993). Contra un enemigo mortal e invisible. Barcelona: Crítica.

Cori, Anne, Ferguson, Neil, M, Fraser, Christophe y Cauchemez (20I3). "A New Framework and Software to Estimate Time-varying Reprodution Numbers during epidemics". American Journal of Epidemiology, vol. 178, núm. 9, septiembre, 15, 1505-1512.

Davis, Mike (2005). The Monster at out Door.The GlobalThreat of Avian Flu. New York:The New Press.

Davis, Mike (2020a). "Entra en escena el monstruo". New Left Review, 122, mayo-junio, II-19.

- (2020b). The Monster enters. Covid-19, Avian Flu, and the Plagues of Capitalism. New York: O/R Books. Libro electrónico.

Foster, John Bellamy y Suwandi "CovID-19 y capitalismo catastrófico". Disponible en: https://www.sinpermiso. info/textos/ covID-19-y-capitalismo-catastrofico.

Grmek, Mirko D. (2019). Pathological Realities. Essays on Disease, Experiments, and History. New York: Fordham University Press.

Jabr, Ferris. (s/f). "Cómo fue que los humanos desatamos un torrente de nuevas enfermedades". Disponible en: https://www.nytimes.com/es/2020/06/25/magazine/ coronavirus-murcielagos-animales-enfermedades.html. Molina del Villar, América (20I8). "Fuentes y abordajes metodológicos en el estudio de las epidemias: el caso mexicano", Revista Electrónica de Fuentes y Archivos (REFA). Centro de Estudios Históricos "Prof. Carlos S.A. Segreti”. Córdoba (Argentina), año 9, número 9, 78-95. Morse, Stephen S.; Mazet, Joanna A. K.; Woolhouse, Mark et al. (20I2). "Prediction and Prevention of the Next Pandemic Zoonosis”. Lancet; 380, 1956-65. 
Bibliografía
Quammen, David (2020). Contagio. La evolución de las pandemias. Debate. Libro electrónico.

Quammen, David (20I2). Spillover. Animals and Nex Human Pandemic. London W.W. Norton y Company. - (20I4). Ébola. La historia de un virus mortal. Libro electrónico.

Pamplona, Francisco (2016).“Epidemias y política. Reflexiones sobre el 'estado de excepción' desde la sociología jurídica”. En Josefina Callicó y Evaristo Jaime González (Coord.). Estudios y testimonios en honor al Dr. Manuel Rodríguez Lapuente. Gobierno del Estado de Jalisco, Guadalajara, 4I-66.

Snowden, Frank M. (2019). Epidemics and Society. From the Black Death to the Present. New Haven:Yale University Press.

Spinney, Laura (s/f). El jinete pálido. 19/8: La epidemia que cambió el mundo. Libro electrónico.

Sontag, Susan (1991). La enfermedad y sus metáforas. El sida y sus metáforas. Barcelona: Muchnik.

Traverso, Enzo (s/f)."El estado de emergencia sanitaria corre el riesgo de ejercer un control total sobre nuestras vidas". Entrevista con Matieu Dejean. Disponible en: https://vientosur.info/el-estado-de-emergencia-sanitaria-corre-el-riesgo-de-ejercer-un-control-total/.

Wallace, Rob; Liebman,Alex; Chaves, Luis Fernando y Rodrik Wallace (s/f). "El Covid-19 y los circuitos del capital". IZQweb. Disponible en: http://izquierdaweb.com/elcovID-19-y-los-circuitos-del-capital/.

Wallace, Robert G. ; Bergmann, Luke et al. (20I5). "The Dawn of Structural One Health:A New Science Tracking Disease Emergence along Circuits of Capital". Social Science y Medicine, 129, 68-77.

Watts, Sheldon (1997). Epidemias y poder. Historia, enfermedad, imperialismo. Barcelona: Editorial Andrés Bello. 
Xiaoming, Ai (2020). “Diario de Wuhan”. New Left Review, I22, mayo-junio, 20-27.

Zimmer, Carl (2020). Un planeta de virus. Capitán Swing. Libro electrónico.

\section{Fuentes}

CCPNs. Consejo Consultivo del Programa Nacional de Solidaridad. El combate a la pobreza. El Nacional, México, 1990. conapo-conagua. Consejo Nacional de Población y Comisión Nacional del Agua. Indicadores socioeconómicos e índice de marginación municipal 1990. México, 1993.

CONAPO. Consejo Nacional de Población. Desigualdad regional y marginación municipal en México, 1990. México, 1994. CONAPO. Consejo Nacional de Población. Índices de marginación 2000. México, $200 \mathrm{I}$.

conAPO. Consejo Nacional de Población. La población de México en el nuevo siglo. México, 200I.

cONAPO. Proyecciones de Población. Disponible en: https:// datos.gob.mx/busca/dataset/proyecciones-de-la-poblacion-de-mexico-y-de-las-entidades-federativas-2016-2050.

INEGI. x Censo General de Población y Vivienda, 1980.

INEGI. XI Censo General de Población y Vivienda, 1990.

INEGI. XII Censo General de Población y Vivienda, 2000.

INEGI. XIII Censo de Población y Vivienda, 2010.

INEGI. Estadísticas históricas de México, México 1994. (Hay versión electrónica).

OCDE y Banco Mundial. Panorama de la salud: Latinoamérica y el Caribe 2020. París, 2020

Presidencia de la República. Sexto informe de Gobierno 2012. México. Poder Ejecutivo Federal 2012.

Presidencia de la República. Sexto informe de Gobierno 2018. México. Poder Ejecutivo Federal 2018.

Presidencia de la República. Primer informe de Gobierno 20182019. México. Poder Ejecutivo Federal 2019. 
Bibliografía SSA. Lineamiento estandarizado para la vigilancia epidemiológica y por laboratorio de la enfermedad respiratoria viral, abril 2020. Secretaría de Salud, México, 2020.

SSA. Primer informe de labores 20 / 8-2019. Secretaría de Salud, México, 2019.

SSA. Página electrónica con toda la información sobre la pandemia de covID-19 en México. Disponible en:https:// coronavirus.gob.mx/datos/.

SSA. Secretaría de Salud. Programa Nacional de Salud 200 I2006. La democratización de la salud en México. Hacia un sistema universal de salud. México, 2001. 